06;07;09

\title{
Синтез легированного кислородом графитоподобного нитрида углерода из тиомочевины
}

\author{
(C) Н.М. Денисов ${ }^{1}$, Е.Б. Чубенко ${ }^{1, \uparrow, ~ В . П . ~ Б о н д а р е н к о ~}{ }^{1}$, В.Е. Борисенко ${ }^{1,2}$ \\ ${ }^{1}$ Белорусский государственный университет информатики и радиоэлектроники, Минск, Беларусь \\ ${ }^{2}$ Национальный исследовательский ядерный университет „МИФИ“, Москва, Россия \\ ฯ E-mail: eugene.chubenko@gmail.com
}

Поступило в Редакцию 28 августа 2018 г.

Получен легированный кислородом графитоподобный нитрид углерода $\left(\mathrm{g}-\mathrm{C}_{3} \mathrm{~N}_{4}\right)$, синтезированный при термообработке тиомочевины при $450-550^{\circ} \mathrm{C}$. Показано, что с ростом температуры отжига увеличивается концентрация кислорода в $\mathrm{g}_{-} \mathrm{C}_{3} \mathrm{~N}_{4}$ и происходит уменьшение ширины запрещенной зоны материала с 2.64 до $2.47 \mathrm{eV}$. Полупроводниковые свойства легированного кислородом $\mathrm{g}-\mathrm{C}_{3} \mathrm{~N}_{4}$ подтверждены его высокой фотокаталитической активностью, установленной по обесцвечиванию в его присутствии водного раствора Родамина В при облучении видимым светом.

DOI: 10.21883/PJTF.2019.03.47274.17503

Графитоподобный нитрид углерода $\left(\mathrm{g}-\mathrm{C}_{3} \mathrm{~N}_{4}\right)$ - наиболее термодинамически стабильная фаза нитрида углерода [1], состоящая, подобно графиту, из слоев моноатомной толщины, удерживаемых вместе силами Ван-дерВаальса. Ширина запрещенной зоны $\left(\Delta E_{g}\right)$ объемного g- $\mathrm{C}_{3} \mathrm{~N}_{4}$ составляет $2.70 \mathrm{eV}$ [2], поэтому он способен поглощать излучение видимого диапазона. Это позволяет использовать g- $\mathrm{C}_{3} \mathrm{~N}_{4}$ в фотокаталитических процессах: очистке воды, генерации водорода и синтезе углеводородов из углекислого газа [3]. Фотокаталитическая активность $\mathrm{g}-\mathrm{C}_{3} \mathrm{~N}_{4}$ может быть увеличена путем введения сужающих запрещенную зону легирующих примесей [4], например таких, как кислород [5,6]. Однако ввиду его высокой химической активности введение кислорода в g- $\mathrm{C}_{3} \mathrm{~N}_{4}$ требует оптимального сочетания метода синтеза и материала-прекурсора [2].

Нами установлено, что легированный кислородом $\mathrm{g}-\mathrm{C}_{3} \mathrm{~N}_{4}$ может быть синтезирован путем термической полимеризации, проводимой в замкнутом объеме воздушной атмосферы, при использовании в качестве прекурсора тиомочевины. Для синтеза легированного кислородом $\mathrm{g}_{-} \mathrm{C}_{3} \mathrm{~N}_{4} 2 \mathrm{~g}$ тиомочевины помещали в фарфоровые тигли объемом $25 \mathrm{~cm}^{3}$, плотно закрывали их крышкой и подвергали термообработке при 450, 500 или $550^{\circ} \mathrm{C}$ в течение $4 \mathrm{~h}$. После естественного остывания тиглей полученный материал превращали в порошок путем перетирания в агатовой ступке.

Структура материала исследовалась методом растровой электронной микроскопии (РЭМ) в микроскопе Hitachi S-4800. Состав изучался методами энергодисперсионной рентгеновской (ЭДР) и инфракрасной фурьеспектроскопии на спектрометрах Bruker QUANTAX 200 и Bruker Vertex 70 соответственно. Ширина запрещенной зоны $\Delta E_{g}$ определялась при комнатной температуре по положению максимума на спектрах фотолюминесценции, возбуждаемой монохроматическим излучением с длиной волны $345 \mathrm{~nm}$, выделенным из спектра излучения ксеноновой лампы, которые регистрировались с помощью монохроматора-спектрографа Solar TII MS 7504 i.

Фотокаталитическая активность синтезированного материала оценивалась на основе описанной нами ранее методики $[7,8]$ по степени разложения тестового красителя Родамин В. В чашку Петри помещали $3 \mathrm{ml}$ водного раствора Родамина В с концентрацией $10 \mathrm{mg} / \mathrm{l}$ и добавляли в него $10 \mathrm{mg}$ полученного порошка. Одну контрольную чашку Петри с суспензией выдерживали в темноте, а другую облучали видимым светом от светодиодной лампы мощностью $20 \mathrm{~W}$, установленной на высоте $5 \mathrm{~cm}$ над ней, в течение $30 \mathrm{~min}$ при постоянном перемешивании суспензии. Далее для седиментации порошка контрольную и рабочую суспензии выдерживали в темноте в течение $20 \mathrm{~h}$ и затем с помощью спектрофотометра Proscan MC 121 регистрировали спектры поглощения очищенных от порошка растворов.

В результате термообработки тиомочевины при $450-550^{\circ} \mathrm{C}$ внутри тиглей образовывался пористый хрупкий желтый материал. Проведенный РЭМ-анализ

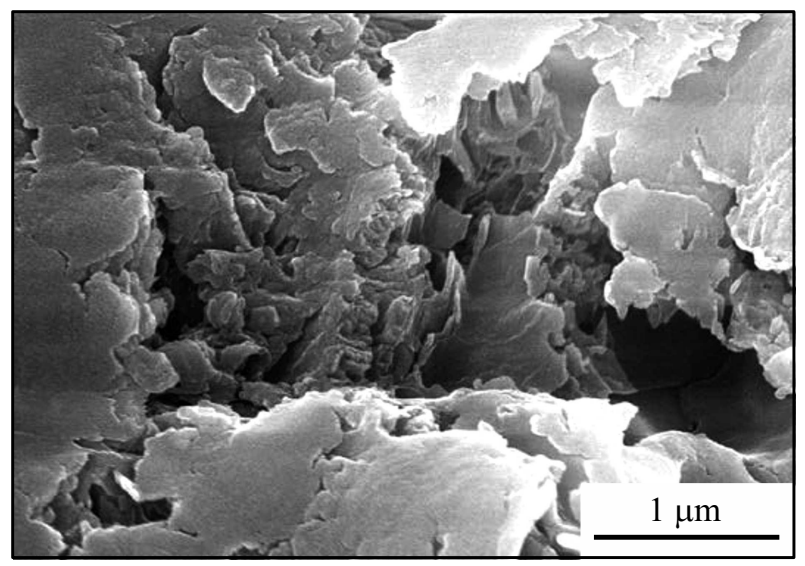

Рис. 1. Микрофотография поверхности материала, синтезированного из тиомочевины при $450^{\circ} \mathrm{C}$. 
показал, что структурно этот материал представляет собой агломерацию плоских достаточно крупных (размером до нескольких микрометров) и мелких (размером менее $50 \mathrm{~nm}$ ) частиц толщиной до нескольких нанометров. Их типичный вид иллюстрирует рис. 1 на примере материала, синтезированного при $450^{\circ} \mathrm{C}$. С повышением температуры синтеза размер и количество крупных частиц уменьшается. Это может быть связано как с частичным сгоранием материала, так и с ранее отмечавшейся склонностью $\mathrm{g}^{-} \mathrm{C}_{3} \mathrm{~N}_{4}$ к расслоению при повышенных температурах [9].

По данным ЭДР-спектроскопии материал, синтезированный при $450^{\circ} \mathrm{C}$, содержит 32.1 at.\% углерода, 63.1 at.\% азота и 4.8 at.\% кислорода. С повышением температуры синтеза до $550^{\circ} \mathrm{C}$ содержание углерода практически не изменяется (32.3 at.\%), в то время как содержание азота уменьшается до 60.2 at.\%, а содержание кислорода увеличивается до 7.5 at.\%. Несмотря на присутствие серы в тиомочевине, атомов серы в составе полученного из нее материала в пределах чувствительности метода ЭДР-спектроскопии не обнаружено.

ИК-фурье-спектры синтезированного материала, пример которых приведен на рис. 2 для температуры син-

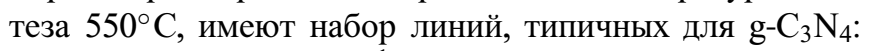
поглощение на $810 \mathrm{~cm}^{-1}$ соответствует радиальной колебательной моде гептазина [2], а полосы поглощения в диапазоне $1200-1600 \mathrm{~cm}^{-1}$ соответствуют колебательным модам гетероциклических соединений углерода и азота [5]. Наличие этих полос поглощения неоднократно наблюдалось ранее и позволяет однозначно идентифицировать синтезированный материал как g- $\mathrm{C}_{3} \mathrm{~N}_{4}$. Поглощение в диапазоне $3000-3500 \mathrm{~cm}^{-1}$ соответствует связям О-Н и $\mathrm{N}-\mathrm{H}$ [5], что индицирует пассивацию водородом из прекурсора связей основных компонентов (углерод, азот) на торцах образовавшихся частиц нового материала. Следует отметить интенсивную полосу поглощения при $1205 \mathrm{~cm}^{-1}$, которая становится наиболее ярко выраженной с повышением температуры синтеза. Данная полоса относится к колебательной моде растяжения связей $\mathrm{C}-\mathrm{O}$ [10] и служит признаком замещения атомов азота в $\mathrm{g}-\mathrm{C}_{3} \mathrm{~N}_{4}$ кислородом.

Полученные данные показывают, что синтезированный материал представляет собой легированный кислородом g- $\mathrm{C}_{3} \mathrm{~N}_{4}$, при этом с увеличением температуры синтеза степень легирования кислородом повышается. Избыточное содержание азота в синтезированных материалах (по сравнению со стехиометрическим составом $\mathrm{g}_{-} \mathrm{C}_{3} \mathrm{~N}_{4}$ ) связано с неполной конденсацией продуктов разложения тиомочевины в $\mathrm{g}_{-} \mathrm{C}_{3} \mathrm{~N}_{4}[1]$.

Проведенные фотолюминесцентные и фотокаталитические исследования полученного материала подтверждают наличие у него полупроводниковых свойств, качественно близких к свойствам $\mathrm{g}^{-} \mathrm{C}_{3} \mathrm{~N}_{4}$. Спектры фотолюминесценции имеют один максимум, смещающийся в длинноволновую область с повышением температуры синтеза. Так, для материала, синтезированного при $450^{\circ} \mathrm{C}$, он находится на длине волны $469 \mathrm{~nm}$, а при
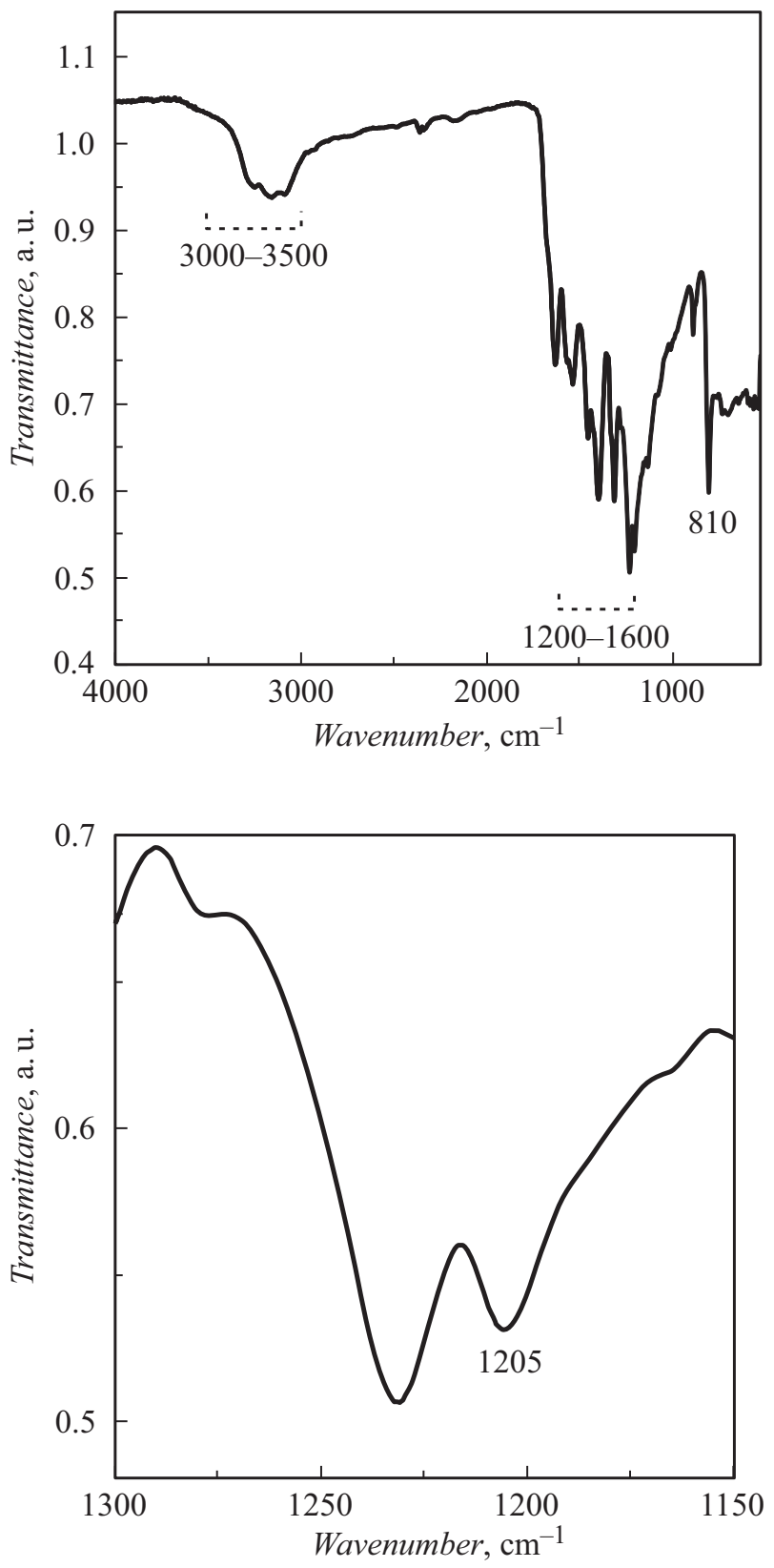

Рис. 2. ИК-фурье-спектры материала, синтезированного из тиомочевины при $550^{\circ} \mathrm{C}$.

$550^{\circ} \mathrm{C}$ - на длине волны $502 \mathrm{~nm}$. С учетом того, что фотолюминесценция в данном случае обеспечивается межзонной рекомбинацией носителей заряда, эти показатели соответствуют $\Delta E_{g}=2.64 \mathrm{eV}$ в материале, синтезированном при $450^{\circ} \mathrm{C}$, и $2.47 \mathrm{eV}$ в материале, синтезированном при $550^{\circ} \mathrm{C}$. Это меньше, чем у нелегированного бездефектного $\mathrm{g}_{-} \mathrm{C}_{3} \mathrm{~N}_{4}(2.70 \mathrm{eV}[2])$. Уменьшение $\Delta E_{g}$ в синтезированном нами материале коррелирует с увеличением содержания в нем кислорода, что согласуется с данными, представленными в $[5,6]$. Не следует также исключать роли увеличенной степени полимеризации молекул $\mathrm{C}_{3} \mathrm{~N}_{4}$ при повышении температуры синтеза, в 
результате чего усиливается $\pi$-сопряжение в структуре этих молекул и становится возможной релаксация электронов с $\sigma^{*}$ - на $\pi^{*}$-орбиталь [11]. Однако этот механизм представляется менее значимым в исследуемом сильно легированном кислородом $\mathrm{g}-\mathrm{C}_{3} \mathrm{~N}_{4}$.

Наивысшую фотокаталитическую активность в обесцвечивании водного раствора тестового красителя Родамин В показал материал, синтезированный при $550^{\circ} \mathrm{C}$. При его использовании полное обесцвечивание раствора, свидетельствующее о полном разложении красителя, достигнуто за $30 \mathrm{~min}$ облучения. За это время контрольные раствор Родамина В, облученный без порошка синтезированного материала, и раствор с порошком, выдержанный в темноте, визуально не обесцветились и характеризовались снижением интенсивности максимума полосы поглощения Родамина В (на длине волны $556 \mathrm{~nm})$ не более чем на $10 \%$.

Таким образом, нами экспериментально показана принципиальная возможность синтеза легированного

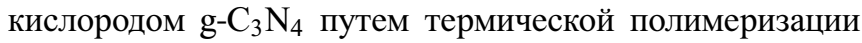
тиомочевины в замкнутом объеме воздушной атмосферы при $450-550^{\circ} \mathrm{C}$. В зависимости от температуры отжига $\Delta E_{g}$ синтезированного материала изменяется от $2.64 \mathrm{eV}$ при концентрации кислорода 4.8 at.\% до $2.47 \mathrm{eV}$ при концентрации кислорода 7.5 at.\%. Полученные данные показывают возможность практического использования легированного кислородом g- $\mathrm{C}_{3} \mathrm{~N}_{4}$ в фотокатализе и для создания светоизлучающих структур видимого диапазона.

Авторы выражают благодарность Д.В. Жигулину за исследование экспериментальных образцов методами РЭМ и ЭДР-спектроскопии, а также С.М. Завадскому за исследование образцов методом инфракрасной спектроскопии с преобразованием Фурье.

Работа выполнена в рамках заданий ГПНИ Республики Беларусь „Конвергенция“ 3.2.04, „Фотоника, опто- и микроэлектроника, 2.1.02 и „Физическое материаловедение, новые материалы и технологии“ 2.21.

\section{Список литературы}

[1] Ong W.J., Tan L.L., Ng Y.H, Yong S.T., Chai S.P. // Chem. Rev. 2016. V. 116. N 12. P. 7159-7329.

[2] Wen J., Xie J., Chen X., Li X. // Appl. Surf. Sci. 2017. V. 391. P. $72-123$

[3] Zhang X., Xie X., Wang H., Zhang J., Pan B., Xie Y. // J. Am. Chem. Soc. 2013. V. 135. N 1. P. 18-21.

[4] Jiang L., Yuan X., Pan Y., Liang J., Zeng G., Wu Z., Wang H. // Appl. Catal. B. 2017. V. 217. P. 388-406.

[5] Fu J., Zhu B., Jiang C., Cheng B., You W., Yu J. // Small. 2017. V. 13. N 15. P. 1603938 (1-9).

[6] Li J., Shen B., Hong Z., Lin B., Gao B., Chen Y. // Chem. Commun. 2012. V. 48. N 98. P. 12017-12019.

[7] Denisov N.M., Chubenko E.B., Bondarenko V.P., Borisenko V.E. // J. Sol-Gel Sci. Technol. 2018. V. 85. N 2. P. $413-420$.

[8] Денисов Н.М., Баглов А.В., Борисенко В.Е. // Неорган. материалы. 2017. Т. 53. № 2. С. 161-165.
[9] Li Y., Wang M.Q., Bao S.J., Lu S., Xu M., Long D., Pu S. // Ceram. Int. 2016. V. 42. N 16. P. 18521-18528.

[10] Zeng Y., Liu X., Liu C., Wang L., Xia Y., Zhang S., Luo S., Pei Y. // Appl. Catal. B. 2018. V. 224. P. 1-9.

[11] Zhang Y., Pan Q., Chai G., Liang M., Dong G., Zhang Q., Qiu J. // Sci. Rep. 2013. V. 3. P. 1-8. 